\title{
How to Improve Safety on the Offshore Installations
}

\author{
A. Mrozowska \\ Polish Naval Academy, Gdynia, Poland \\ P. Mrozowski \\ Gdynia Maritime University, Gdynia, Poland
}

\begin{abstract}
Reviving is noticeable in the field of oil and gas production located under the seabed. The offshore projects are being implemented. Due to this, the risk of accidents at each stage of production should be considered continually. The offshore market, both oil and gas as well as renewable energy, is estimated to increase steadily in the coming years. Therefore, the operations on the production oil field must be suitably protected at every stage of performing work. The paper describes how important Job Safety Analyses are for proper operations. The main aim of the article is to indicate steps and the best way of performing JSA on board of the offshore installation to reduce the risk of emergency. The selected disasters and major accidents indicate that the conducted activity is exposed to the risk of hazards to the natural environment and to people at every stage of the reservoir exploitation. The authors use the analysis of available international reports, the experience gained while working on different types of the offshore vessels and installations as well as in the Polish offshore company.
\end{abstract}

\section{INTRODUCTION}

Conducting activities related to oil and natural gas exploitation in sea areas is subject to the risk of major accidents, breakdowns, dangerous situations and other events. The fact is that the threat posed by spilled petroleum in sea areas may pose a threat to the life and health of people not only staying on the installation but also as a result of contact with the contaminated natural environment and its degradation for many years. In addition, threats that occurred in the marine exploitation fields show that they negatively affected the regional and global economy and shaped the exploration and production as well as oil prices on the local and global markets [6].
In connection with the above, conducting work requires the use of highly advanced technologies and high-class specialists working in offshore industries.

The events that took place on April 10, 2010 in the Gulf of Mexico began an international debate on improving safety while conducting oil and gas work.

This resulted in the establishment of numerous regulations and coherent actions for operators and owners conducting exploration and production activities in maritime areas, such as: Directive 2013/30/EU. The introduction of the Directive 2013/30/EU aims to reduce the risk of hazards by defining the framework of activities for EU Member States conducting mining operations and, above all, obliging operators and owners to implement appropriate solutions in this area. The Directive lays down minimum requirements in the area of majoraccident prevention related to oil and gas activities in 
maritime areas. The operator must show a number of documents that must be submitted to the competent supervisory authority in connection with the activities carried out.

In addition, the offshore company must establish a safety and environmental management system that is incorporated into the overall management system. It should be noted that in addition to the requirements of the directives, the entity must comply with a number of international and local standards, related to the exploration and production of energy resources located under the seabed.

Moreover, improving safety while conducting work should be considered in a broader sense, which can also be understood as a maritime safety culture.

This means transferring more knowledge and understanding to the matters related to ensuring the safe operations of ships and all activities related to the safe exploitation of the sea resources [4]. Ensuring safety as well as its improving should be considered in terms of an individual, that is, every installation employee as well as supervisors and end with the managers of the installations, owner sand control and supervisory bodies.

The accidents that took place in the marine exploitation fields indicate that they cannot be eliminated, but all measures should be taken to limit them to a maximum. The events are often a sequence of unfavourable events that progress slowly, often in the long-term, or occur suddenly without preceding warning signals. Therefore, the introduction of appropriate safety tools in the phase of planning work and then ensuring proper monitoring of work is fundamental to reducing the risk of a dangerous event.

The paper was based primarily on the experience of the authors gained while working on specialized offshore ships, work on the installation and in the ship owners' office, as well as on various legal regulations, such as: International Safety Management Code, Directive 2013/30 / EU, local legal regulations, including classifiers, such as: Lloyds List Intelligence, European Union Commission reports, Health and Safety Executive UK.

The aim of the article is to indicate safety solutions during routine activities as well as work performed on the basis of written licences, and to discuss the proper implementation of the Job Safety Analysis (JSA). The paper shows fundamental is proper planning, implementation and supervision of both daily and high-risk activities in implementing international postulates in relation to improving safety in the offshore industry.

\section{ANALYSIS OF ACCIDENTS IN THE OFFSHORE INDUSTRY}

Work in the offshore industry is considered as one of the most dangerous because of constant threat due to the type of operation carried out and the impact of the natural environment on work. Activities must be carried out throughout the year, both at high temperatures and extremely low temperatures, during intense rain as well as strong winds. This causes a number of major accidents which occurred in the oil fields or was connected with offshore activities.

The total number of fixed and floating installation is 586 .

The vast majority of offshore installations in EU waters are located in the North Sea. In the Mediterranean Sea, Italy is the most active Member Stat followed by Croatia. In the Black Sea, Romania and Bulgaria has an offshore oil and gas industry. In the Baltic Sea only Poland produces oil and gas [7].

In 2016 there were conducted 735 inspections on the installations. The inspections covered all departments of the installation. There were checked 381 installations. In the Baltic Sea there were four inspections and all installations were checked. During the inspections, indicated that the works were not carried out in according to the procedures. Moreover, discovered that works were not well- planned and documents were not filled correct. The inspections also showed that the crew did not stick to the completed documents, including Job Safety Analysis and Permit To Work, as integrated. As a result, they can lead to accidents, as evidenced by the statistics presented above.

According to Annual EU report 59,5\% of all accidents were category of unintended realize $-59,5$ $\%$ of the total, $26,2 \%$ connected the loss of well control (blowout/diverted activation), 7,1\% failures of safety and environmental critical elements and 4,8 loss of structural integrity. One incident required the evacuation of personnel [8]. According to Summary report if European Comparison published 31 October 2018 from last ten years the rate of fatal injury at has been decreasing. In Poland according to the annual assessments report of health and safety issued by Polish Mining Authorities, in 2018 there were 35 accidents at work, there were no fatalities. It is $1,3 \%$ all accidents at work in mining industry (including activates on shore and at sea) [1].

\section{PROVISIONS OF THE OFFSHORE DIRECTIVE}

The following chapter presents the guidelines of the Directive 2013/30 / EU, which, as already mentioned, was developed to reduce the risk of major accidents associated with oil and gas exploitation. Therefore, it requires identification and management of serious threats, as well as the introduction of effective reaction strategies in the event of their occurrence from the owners and operators conducting operations related to oil and natural gas exploitation. The specificity of the conducted activities indicates that they are subject to the risk of a hazard occurrence. Therefore, at every stage of the operations it is necessary to maintain the safety rules and keep them at the optimal and acceptable level throughout the entire operation. Ensuring the level of safety is the result of the synthesis of elements which interact with each other. These include, among others, external factors, technical factors, operational factors, personal factors, as well as a number of factors which have direct and indirect impact on exploitation, but also support or disrupt the exploitation process. 
The abundance of provisions in the Directive ensures that first of all every person who conducts offshore operations will implement uniform regulations which are imposed on all operators of offshore installations and also will take appropriate measures to prevent major accidents, i.e. to provide complete supervision and responsibility even if it is done by another operator [5].

Therefore, each company has developed and implemented measures necessary to ensure safe working conditions, rules for controlling the risk of occurrence of dangerous events and accidents in terms of minimizing the occurrence of risk, elimination of its consequences as well as general and environmental safety. They have been identified in the functioning systems with safety and environmental management as well as with other occupational health and safety management systems and quality management systems. Each enterprise related to oil and gas operations in maritime areas must have appropriate certificates to meet specific requirements.

\section{SAFETY AND ENVIRONMENTAL MANAGEMENT SYSTEMS}

As already mentioned, the company must establish a safety and environmental management system that becomes an integral part of the management system functioning in the enterprise and a part of the corporate policy related to the control of minimizing the risk related to the activities.

A tool that implements, verifies and improves the safe operation of installations can be established by the above-mentioned regulations such as the ISM Code, environmental standards, safety regulations, classifier regulations and Flag State in accordance with the provisions of point 1.4 of the ISM Code, a Safety Management System must be developed - SMS, which obliges the owner of the installation and the operator as the entity responsible for the safety of the units to establish and implement SMS on the units and in the office [3].

In the case of offshore installations, this applies to Mobile Offshore Drilling Units or fixed installations if the Flag deems it appropriate, as is the case with platforms in the Baltic Sea under the Polish flag.

It is a system that contains a set of procedures, instructions and guidelines defined for a given installation, taking into consideration its activities. In accordance with the provisions of the ISM Code, a regulation must be developed and implemented in the field of procedures and operations on board, both routine / daily, which do not require the issuance of appropriate permit to work, as well as those for which issuing the required permit to work is necessary to perform a given operation .

The regulation of operations rules is aimed at increasing the level of safety during the execution of a given task on the installation, both for people performing it, as well as for the environment and property.
It is obvious that the whole crew has an impact on the safe operation of the unit. It should be emphasized that the work of the crew is burdened with the constant risk of a dangerous event. In addition, rest takes place constantly in the same place where the installation's crew work, it is often loud, uncomfortable and exposed to unpredictable situations threatening health and even life. As a result, decision making can be limited or slowed down. Proper management of operations as a protection against a series of adverse events requires the implementation of procedures defined in the implemented system.

Therefore, the Safety Management System on board, despite its specific framework and conditions included in the procedures, should support the possibility of taking appropriate actions. The developed procedures do not exclude $100 \%$ of human error or device failure. There are another safety measure, which primarily causes an increase in awareness of hazards during operations, and thus improvement of work safety, such as risk assessments, analysis of risk assessments, control of whole work process, safety meetings and close up review of work steps.

\section{THE RULES OF SAFE OPERATIONS ON INSTALLATIONS}

Performing operations on installations is carried out in accordance with specific requirements based on maritime and mining regulations, defined, among others, by the International Association of Drilling Contractors, the Society of Petroleum Engineers and, first of all, by "Good Drilling Practice". Service as well as maintenance and inspections of individual components are also carried out in accordance with documented procedures and inspection based on the Preventive Maintenance System (PM System).

This part of the study will cover the stages of safe execution of non-routine operations which may result in emergencies. Figure 1 presents a set of formal requirements necessary to perform operations. These operations must be performed on the basis of a written Permit To Work (PTW). A work permit is a document issued by the person supervising the work every time it is needed. Examples of operations are as follows:

- work on hydrocarbon transmission systems,

- hot work,

- pressure system checking,

- work at heights,

- outboard operations,

- cargo transfer operations with a crane,

- operations in enclosed spaces,

- electrical operations (electrical isolation),

- underwater operations performed with the participation of a diver.

The document is divided into several parts, containing, among others, a description of the operations, identification of potential hazards, applied protection measures, comments and signatures of all participants of the operations. Due to the fact that there is a risk of accident or dangerous situation, the so-called Job Safety Analysis (JSA) is an 
integral part of such a document (before a work permit is issued). JSA is a tool used for systematic assessment of hazards before the commencement of a given operation and determination of activities eliminating or limiting identified hazards for individual stages, both during the preparation and execution of a given operation. The JSA set should be specified for all operations performed on the installation and the generic JSA should be completed in case of the lack of information.

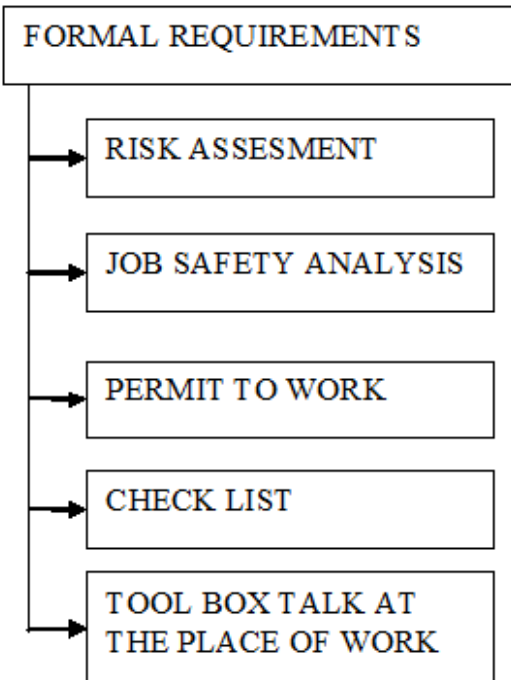

Figure 1. Presents a set of formal requirements necessary to perform operations.

A part of the work permit is also the Tool Box Talk carried out by the supervisors. It aims to discuss how to perform a given job, to indicate hazards and mechanisms that reduce the risk of an accident during work, assignment of operations and other safety issues during the operations. This conversation takes place before the commencement of operations and the checklist is attached to the work permit.

\section{ANALYSIS OF THE VALIDITY OF THE JSA DEVELOPMENT}

The JSA development is required when the hazards and risks associated with the operations are not sufficiently defined and controlled through the applicable procedures, instructions and permits/licences (including work permits, work/position instructions, technological instructions, manuals for machines and devices, etc.). Its aim is to reduce the risk of an accident.Therefore, JSA is an important element of safety and is developed by a team consisting of , among others:

- work contractor,

- the person allowing to perform operations (Supervisior)

- HSE Officer,

- specialists in particular industries depending on the scope of work,

- and other persons designated by the person responsible for JSA or whose work it concerns. The JSA sequence consists of the following steps and is shown in Figure 2.
The JSA organizer manages all the tasks related to the JSA implementation. $\mathrm{He}$ is responsible for collecting all necessary data and specific conditions for safe work performance, identifying people involved in the JSA development, calling a meeting and making appropriate entries.

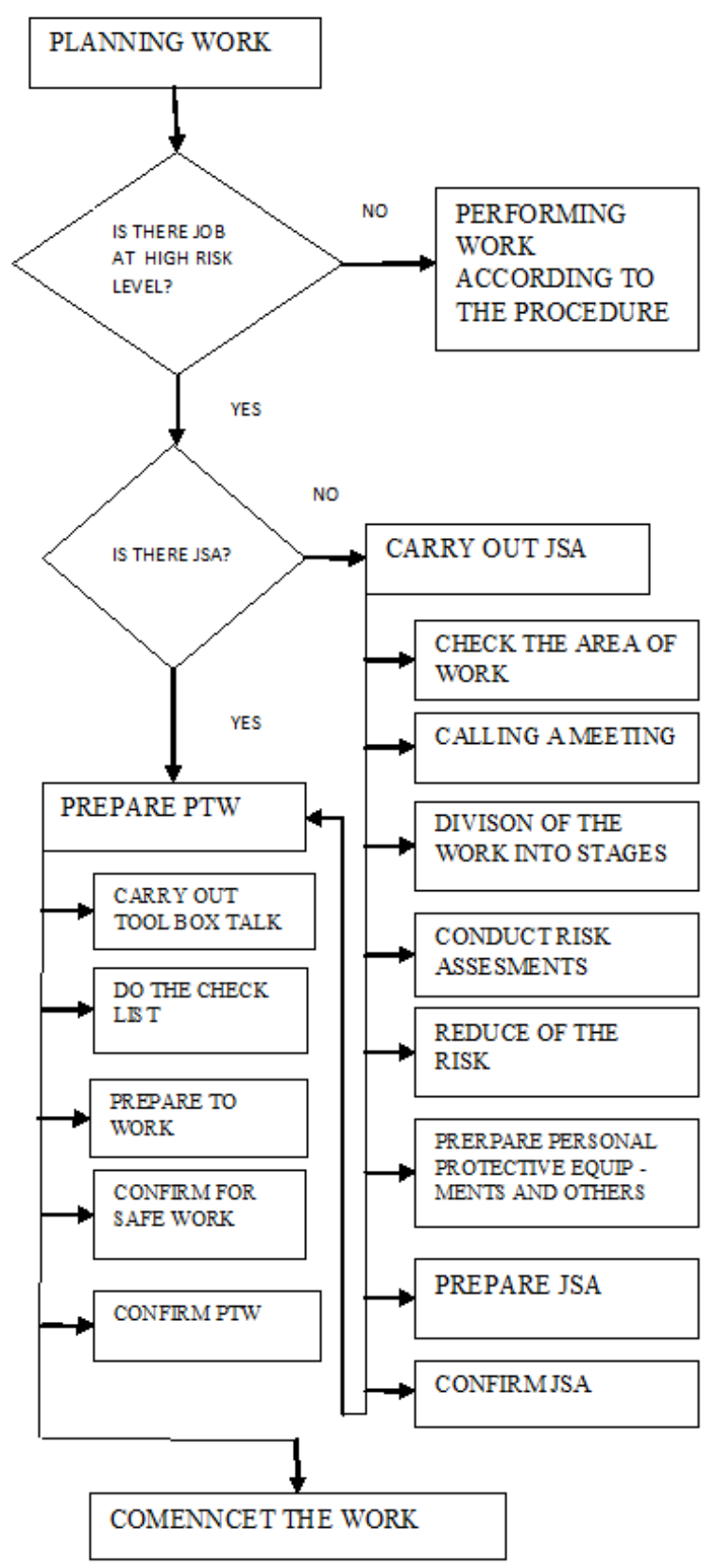

Figure 2. Steps of planning work.

The tasks of the JSA team include, among others:

- division of the planned work into individual stages in the order of their execution. If possible, it is advisable to inspect the place / area where the work will be carried out,

- discussion of individual stages of work,

- identification of hazards related to work performed and determination of their impact by estimating risk levels before and after applying risk elimination measures and methods,

- determination and recording of each activity of operations to limit and control risks, together with assigning responsibility for individual actions, 
while maintaining the principle of risk reduction to a possibly lower level at an acceptable level,

- identification of personal protective equipment (PPE) required during the operation and determination of other solutions reducing the risk and securing work,

- preparation of JSA

- submission of JSA for approval by the manager, or a designated person in the area where the operations will be performed.

The following issues are considered when developing a JSA:

1 Have operations and hazards associated with them, as well as the method of performing operations been recorded in the appropriate procedures and / or instructions or does the implementation require a derogation from the established rules?

2 Are there any derogations in the planned work in relation to the established procedures?

3 Have all hazards and risks related to work been included in the work permit?

4 Are all risk factors determined and controlled by the Work Permit?

5 Have there been accidents / potentially accidental events, failures in this type of work?

6 Is the work considered to be a complex job, with an increased risk, or will be performed by many subcontractors?

7 Do employees have adequate experience in performing the planned work?

8 Are new devices or work methods, which have not been recorded in the appropriate procedures and / or instructions, used for operations?

\section{CONDITIONS FOR SAFE OPERATIONS. AREAS OF SPECIAL SENSITIVITY (WEAK POINTS) WHEN PLANNING WORK - DISCUSSION}

During a well-planned and prepared action, the risk of an accident is reduced to an acceptable level. However, to maintain this level throughout the entire working time, it is necessary to follow the established rules. In case of derogations, various types of hazardous situations and accidents may occur. They may be caused by errors made at the early stage of work planning, including the development of JSA and the issuing of work permits. Figure 3 presents weak points (areas of special sensitivity) which appear at the planning stage of operations.

If the operations start with errors or weak points occur, the work stage is exposed to the risk of an accident and the occurrence of further weaknesses that may lead to a sequence of adverse events, and thus the accident.

In the next stage, which is the implementation of operations, the biggest mistake can be a lack of or incomplete JSA. Work permits may also not be issued or be incomplete. As a result, the commencement of operations takes place without proper regulations and preparation of the job sites, for example: bunkering the fuel without the preparation of the place and without approval of the permit, and the crew explains that everything will be arranged soon, that they know what to do.

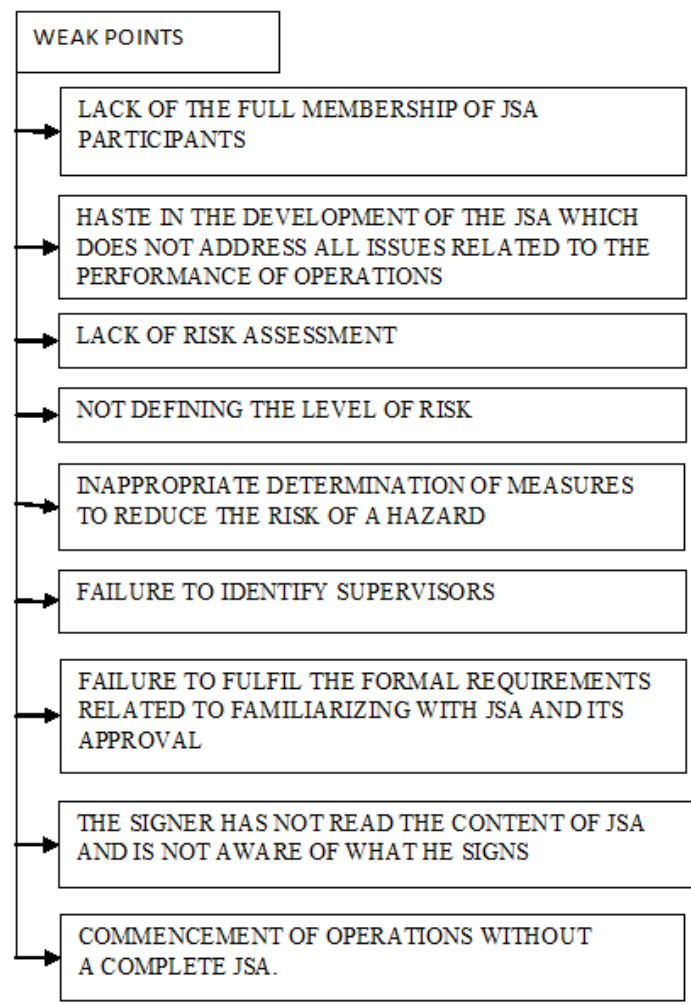

Figure 3. Weak points of planning works.

It may also turn out that the permit was issued but the supervisor did not check the place of work which was not properly prepared. Other issues include:

- Failure to follow procedures and arrangements,

- Lack of established communication routes, safeguards and PPE,

- Lack of the work leader - a person who knows the job, as well as a lack of knowledge of the machine operation / performing the work - performing work by operators with insufficient experience,

- Failure to follow the manufacturer's instructions and good practice

- Not informing other departments / people about conducting operations, interruption at work or completion of work,

- The person supervising the operations supervises several operations, e.g. operations in two tanks controlled by one supervisor. Another example is hot work without the proper location of fire protective equipment and without the person supervising the work or switching off the detectors in the place of work.

- Work permit not included,

- Overload of operations,

- A new crew member joined the operations without getting acquainted with JSA and specificity of operations, e.g. reloading. If he wants to join in the operations, he is obliged to contact the supervisor, understand the scope of work, approve the requirements and regulations with signature and then proceed to work.

\subsection{Improving the effectiveness of JSA}

The solutions introduced are intended to eliminate irregularities and errors at an early stage of work. However, the solutions that have already been implemented are not always correct. The analyses and 
inspection of the applied solutions should be carried out in order to improve the quality of work, identify weak points, eliminate recurring errors and thus improve safety. One of the ways to achieve this is to conduct training sessions in the form of an open discussion aimed at exchanging views, applied practices and experiences among installation operators as well as specialists from various industries or experts. During such discussions everyone has the right to express themselves, and indeed it is welcome if they get involved in the debate, because it is related to a very important issue, namely the increase in the awareness of the working environment and the risks that may occur in it.

Owing to the awareness of hazards, employees are indirectly forced to make comments and inform about irregularities. In accordance with the provisions of Directive 2013/30 / EU such approach to work must be appreciated and rewarded. The company must develop a motivational system for employees to detect irregularities, minimize the risk of accidents and reward them for such attitudes. The implemented systems may include various solutions, which include: electronic safety and health at work portals, where each employee can individually report dangerous situations, periodic employee evaluations, as well as incentive systems, with specified prize amounts [2].

Another important factor in improving the quality of JSA is the analysis as to whether the work has already been carried out and whether there has been an accident while performing the operations. If so, the accident report must be discussed in detail and the report results must be considered. An accident does not have to concern a given installation / area on which the work is planned, but it could have taken place somewhere else.

During the meeting devoted to health and safety at work, crew of the installations were asked questions about their personal application of principles concerning the safe performance of operations. 34 participants took part in the survey.

The first question was: Do you sign work permits before you start work? 100\% employees responded positively. The next question was related to getting acquainted with the work permit. $79 \%$ of the respondents said 'yes', whereas 21\% admitted that they did not get acquainted with PTW.

Then the issue of Tool Box Talk was discussed. $72 \%$ responded positively and said they were participating in the talks and $21 \%$ said they did not participate because they did not have time or heard it many times, while $7 \%$ said they did not remember. The employees were also asked the question: Have they ever had doubts about the safety at work? The response of $39 \%$ was positive and of $61 \%$ was negative. In terms of doubts the respondents referred mainly to a large number of operations they had to perform, lack of proper supervision and communication during operations.

The conducted surveys indicate the functioning of the documentation during the performance of operations, however, it is not fully sufficient. Such a short survey shows that safety issues are functioning, but they require continuous improvement. The authors of the article will continue the analysis of safety on sea units in their further research.

\section{CONCLUSIONS}

The implementation of the above elements of maintaining the level of safety on the ship, as well as increasing its level, is established by the manager and must be strictly observed by the ship's crew members. Failure to meet the formal requirements may cause an accident and result in the lack of possibility to recreate the sequence of events that led to it. The functioning safety management system is primarily used to identify such activities early enough to take necessary actions or to avoid their occurrence.

Despite the use of work permits for many years, the occurrence of dangerous events or potentially dangerous events has been observed in drilling. In order to increase work safety, additional analyses of the safety level of individual operations have been carried out, by "breaking" individual operations into sequences and presenting the correct methods of their execution, and presenting the hazards occurring while performing these operations.

\section{REFERENCES}

[1] Assessment of work safety, mining rescue and general safety in connection with mining and geological activities in 2017, 2018 Katowice.

[2] Directive 2013/30/EU of the European Parliament and of the council of 12 of June 2013 on safety of offshore oil and gas operations and amending Directive 2004/35/EC. L.178/66 official Journal of the EU 28.6.2013.

[3] International Safety Management Code ISM Code and guidelines on implementation of the ISM Code 2014 Edition, London, IMO London 2014.

[4] Królikowski, A. Mrozowska, A. Wróbel, R. 2015 Safety culture in management system of safe operation of ships and pollution prevention, Zeszyty Wydziału Nawigacyjnego no 30.

[5] Mrozowska, A. 2018. Review of the provisions of the European Parliament and of the Council Directive 2013/30/UE on safety of offshore oil and gas operations. Polityka Energetyczna - Energy Police Journal, AGH, 2018, Volume 21 issue 4 pages

[6] Offshore Statistic \& Regulatory Activity Report 2017, HSE, UK

[7] Annual Report on the safety of offshore oil and gas operations in the European Union for the Year 2016, Brussels, 17/08/2018, no COM (2018) 595). 